\title{
EFEITO DO SISTEMA DE CRIAÇÃO E DO AMBIENTE SOBRE A QUALIDADE DE OVOS DE POEDEIRAS COMERCIAIS
}

Nerandi Luiz Camerini², Daniele Lopes de Oliveira ${ }^{3}$, Rafael Costa Silva ${ }^{4}$, José Wallace Barbosa do Nascimento ${ }^{5}$, Dermeval Araújo Furtado ${ }^{6}$.

\section{RESUMO}

Este estudo foi realizado com o objetivo de avaliar os efeitos de dois sistemas de criação (gaiola enriquecida e sistema alternativo) na qualidade de ovos de aves poedeiras e a influência de três condições ambientais. O experimento foi conduzido durante três períodos experimentais de 28 dias. Foram utilizadas 36 aves da linhagem Dekalb White em cada sistema de criação com 27 semanas de idade, respectivamente. Avaliou-se a qualidade dos ovos produzidos em um delineamento inteiramente casualizado 2x6 (dois sistemas de criação e seis repetições) com temperaturas de $20{ }^{\circ} \mathrm{C}, 26{ }^{\circ} \mathrm{C}$ e $32{ }^{\circ} \mathrm{C}$ e umidade relativa de $60 \%$ em ambiente controlado. Para a análise da qualidade dos ovos foram avaliados o peso dos ovos, a unidade de haugh, a gravidade específica, pH da clara e da gema. Não foram observadas grandes diferenças na qualidade dos ovos entre os sistema de criação, exceto no pH da gema e da clara. Conclui-se que o sistema de criação em gaiola enriquecida e no sistema alternativo não apresentou grandes diferenças quanto á qualidade dos ovos combinadas com as condições ambientais.

Palavras-chave: peso do ovo, gravidade específica, unidade haugh, $\mathrm{pH}$ da gema e $\mathrm{pH}$ da clara.

\section{ABSTRACT \\ EFFECT OF THE REARING SYSTEM AND THE ENVIRONMENT ON EGG QUALITY IN COMMERCIAL POULTRY FACILITIES}

This study was conducted in order to evaluate the effects of two rearing systems (enriched cage and alternative systems) on the egg quality of laying hens and the influence of three environmental conditions. The experiment was conducted during three experimental periods of 28 days each. The 36 Dekalb White breed was used in each rearing system, with 27 weeks of age, respectively. Quality of eggs produced was evaluated in a completely randomized design $2 \times 6$ (two rearing systems and six replicates) at $20^{\circ} \mathrm{C}, 26^{\circ} \mathrm{C}$ and $32{ }^{\circ} \mathrm{C}$, and relative humidity of $60 \%$ in a controlled environment. For the analysis of egg quality the factors evaluated were egg weight, Haugh unit, specific gravity, yolk and egg white $\mathrm{pH}$. There were no major differences in egg quality among the rearing systems, except for $\mathrm{pH}$ of egg yolk and white. It is concluded that the rearing system in the enriched cage and alternative system present no major differences in the quality of eggs combined with environmental conditions.

Keywords: egg weight, specific gravity, Haugh unit, yolk and egg white $\mathrm{pH}$.

\section{Recebido para publicação em 12/03/2012. Aprovado em 21/06/2013.}

1- Parte da tese de doutorado do primeiro autor

2 - Eng. Agrícola, Professor da Unidade Acadêmica de Serra Talhada, UFRPE - PE: nerandi@gmail.com

3 -Zootecnista, Doutoranda em Enga Agr ${ }^{\text {a }}$ Construções Rurais e Ambiência, UFCG: danielemestre@hotmail.com

4 - Eng. Agrícola, Mestrando em Enga Agrícola - Construções Rurais e Ambiência, UFCG: rafael_brazil@hotmail.com

5 - Eng. Agrícola, Professor da Unidade Acadêmica de Enga Agr ${ }^{\mathrm{a}}$, UFCG, Campina Grande - PB, e-mail: wallace@deag.ufcg.edu.br 6 - Zootecnista, Professor da Unidade Acadêmica de Eng ${ }^{\mathrm{a}}$ Agra ${ }^{\mathrm{a}}$ UFCG, Campina Grande - PB, e-mail: dermeval@deag.ufcg.edu.br

\section{REVENG}




\section{INTRODUÇ̃̃O}

A avicultura de postura se desenvolveu muito nos últimos anos, visando maior produtividade em menor tempo, passando por processo de evolução técnica na genética, alimentação, manejo e sanidade, fatores considerados sustentáculos da avicultura como atividade econômica e importante na produção de alimentos para a população (ALBUQUERQUE, 2004; FURLAN et al., 2006).

$\mathrm{O}$ sistema de criação em gaiolas tornou-se uma das maiores polêmicas acerca do bem-estar animal. O reduzido espaço oferecido e a ausência de caracteres de enriquecimento ambiental impossibilitam ou limitam o repertório de atividades consideradas importantes para o animal, como ciscar, tomar banho de areia, empoleirar etc. (ALVES et al., (2007).

De acordo com (Tauson, 2005), com exceção de poucos países onde existe legislação que proíbe o uso de gaiolas, estas instalações constituem o sistema predominante de criação de aves poedeiras. $\mathrm{Na}$ União Européia, as gaiolas serão permitidas somente até o ano de 2012 (Diretiva 1999/74/CE), o que força a adoção de sistemas alternativos para a produção de ovos.

Considerando que a atividade de produção de ovos tem se tornado cada vez mais competitiva, é importante estar atento, pois é possível estar sempre empregando o máximo de recursos disponíveis (BARBOSA FILHO et al., 2007). Neste sentido, estudos relacionados com a qualidade do ovo têm sido realizados, pois este mantém estreita relação com sua comercialização. Sendo assim, analisar os fatores de qualidade do produto é de suma importância para aceitação dos consumidores.

Esse trabalho foi realizado com o objetivo de comparar a qualidade dos ovos de aves poedeiras criadas em gaiola enriquecida e em sistema alternativo, em três condições ambientais e ambiente controlado.

\section{MATERIAL E MÉTODOS}

As aves utilizadas no experimento foram adquiridas na Universidade Federal da Paraíba UFPB, Areia - PB.

Foram utilizadas 72 aves de postura da Linhagem Dekalb White, com idade inicial de 27 semanas, sendo 36 aves em gaiolas enriquecidas e 36 aves em sistema alternativo.

As aves foram criadas no interior da câmara climática, no Laboratório de Construções Rurais e Ambiência da Universidade Federal de Campina Grande, em dois sistemas de criação: gaiolas enriquecidas (GE) e sistema alternativo (SA), em temperaturas de $20^{\circ} \mathrm{C}, 26^{\circ} \mathrm{C}$ e $32^{\circ} \mathrm{C}$, com Umidade Relativa de $60 \%$. O experimento foi dividido em três períodos de 28 dias, totalizando 84 dias, de acordo com metodologia utilizada por Costa et al, . (2008), sendo que a cada período pré-experimental as aves eram submetidas a sete dias de adaptação e, posteriormente, permaneciam por mais 21 dias para coleta de dados (ovos).

Adotou-se o delineamento inteiramente casualizado $2 \times 6$, dois sistemas de criação (gaiola enriquecida e sistema alternativo) e seis repetições com três condições ambientais $\left(20^{\circ} \mathrm{C}, 26{ }^{\circ} \mathrm{C}\right.$ e $\left.32{ }^{\circ} \mathrm{C}\right)$. As médias foram comparadas pelo Teste de Tukey a 5 $\%$ de probabilidade.

No final de cada período experimental foram escolhidos ao acaso 8 ovos de cada sistema (GE e SA) para a realização da qualidade dos ovos.

Os países da União Européia têm concentrado esforços para desenvolver sistemas de criação de poedeiras comercias sem gaiolas, conhecidos como sistemas alternativos. Estes sistemas oferecem um ambiente mais complexo em que as aves são criadas no chão, em grandes grupos e com um espaço mínimo de $1111 \mathrm{~cm}^{2}$ por ave ou 9 aves por $\mathrm{m}^{2}$. As poedeiras ainda têm acesso a ninhos, poleiros ou ripados em diferentes $\square$ alturas partindo do solo, grande área com cama para banho e dependendo do tipo de sistema, uma parte aberta com acesso a pastos. Por oferecerem maior liberdade de movimento para as aves, os sistemas alternativos melhoram a resistência óssea. Para o sistema alternativo de criação foram construídos 6 boxes experimentais em estrutura de madeira e tela de arame liso hexagonal, com densidade de 6 aves cada box, totalizando 36 aves nesse sistema de criação, com $0,66 \mathrm{~m}^{2}$ de área livre, proporcionando assim $1111 \mathrm{~cm}^{2} /$ ave. Cada box dispunha de um ninho que atende as 6 aves alojadas, de acordo com as normas da União Européia (CEC, 1999). Os boxes foram construídos em madeira com as dimensões de $0,70 \mathrm{~m}$ de altura, por $0,74 \mathrm{~m}$ de largura, e $0,90 \mathrm{~m}$ de profundidade. 
Para a construção de gaiolas enriquecidas, foram desenvolvidos 6 boxes experimentais em estrutura de madeira e tela de arame liso hexagonal, com densidade de 6 aves cada box, totalizando 36 aves nesse sistema de criação, com $0,47 \mathrm{~m}^{2}$ de área livre, proporcionando assim $760 \mathrm{~cm}^{2}$ ave-1. Cada box dispunha de um ninho, que atende a 6 aves alojadas, de acordo com as normas da União Europeia (CEC, 1999). Neste sistema, os ninhos foram alocados no nível do piso, diminuindo o espaço real do box quando comparado com os do sistema alternativo. Os boxes foram construídos em madeira, para o alojamento dos animais com as dimensões de $0,40 \mathrm{~m}$ de altura, por $0,74 \mathrm{~m}$ de largura, e $0,90 \mathrm{~m}$ de profundidade.

Foi instalado em cada um dos boxes, um bebedouro tipo nipple com válvula de regulagem de água, um comedouro tipo calha confeccionado com tubo PVC $75 \mathrm{~mm}$ de cor branca, com $0,85 \mathrm{~m}$ de comprimento, dispondo de $0,13 \mathrm{~m}$ linear para cada ave.

O total de ovos coletados de cada parcela foi pesado durante todo período experimental em balança digital com graduação de $0,01 \mathrm{~g}$. A massa média dos ovos foi calculada pela divisão do número de ovos produzidos no dia, sendo o resultado expresso em gramas.

$\mathrm{O} \mathrm{pH}$ da gema e do albúmem foi feito no final de todas as análises anteriores. Foi separada a gema do albúmem e colocada em copinhos, para posterior homogeneização com um auxilio de um bastão. Em seguida, o pH foi medido com o auxilio de um pHmetro da marca Analyser-300M, calibrado previamente com soluções tampão de $\mathrm{pH}$ 4,0 e 7,0 (BRASIL, 1999).

Para a determinação da gravidade especifica
(GE) dos ovos, utilizou aparelho de pesagem desenvolvido para possibilitar uma adaptação do método descrito por (HEMPE et al., 1988). Esse método se baseia no princípio de Arquimedes e o valor de GE foi obtido usando a equação: GE = massa do ovo/(massa do ovo na água $\mathrm{x}$ correção da temperatura).

Após a pesagem dos ovos, estes foram quebrados e seu conteúdo, (albúmem+gema), colocada numa superfície plana e nivelada. Foi aferida a altura do albúmem $(\mathrm{mm})$, por meio da leitura do valor indicado pelo paquimetro digital "Digimess". De posse dos valores da massa do ovo e altura do albúmem, utilizou-se, então, a fórmula descrita por Pardi (1977), para o cálculo da unidade Haugh:

$$
\mathrm{UH}=100 * \log \left(\mathrm{h}+7,57-1,7 \mathrm{~W}^{0,37}\right)
$$

em que

$\mathrm{h}=$ altura do albúmen (mm); e

$\mathrm{W}=$ massa do ovo $(\mathrm{g})$

\section{RESULTADOS E DISCUSSÃO}

No Quadro 1, são apresentados os valores médios da massa dos ovos, média do $\mathrm{pH}$ da gema e do albúmem, média da gravidade específica e Unidade de Haugh, durante o período experimental nas gaiola enriquecida (GE) e nos sistema alternativo (SA).

A análise estatística das médias das massas dos ovos não revelou diferença significativa $(\mathrm{P}<0,05)$ desta variável com relação ao sistema de criação (GE e SA) e a condição ambiental, respectivamente.

Quadro1. Média da massa dos ovos, gravidade específica, unidade de haugh e pH da gema e da clara.

\begin{tabular}{ccccccc}
\hline $\begin{array}{c}\text { Temperatura do } \\
\text { ambiente }\end{array}$ & $\begin{array}{c}\text { Sistema de } \\
\text { Criação }\end{array}$ & $\begin{array}{c}\text { Massa dos } \\
\text { ovos (g) }\end{array}$ & $\begin{array}{c}\text { Gravidade } \\
\text { específica (g g-1) }\end{array}$ & $\begin{array}{c}\text { Unidade } \\
\text { haugh (\%) }\end{array}$ & pH da gema & pH da clara \\
\hline \multirow{2}{*}{$20^{\circ} \mathrm{C}$} & $\mathrm{GE}$ & $64,22 \mathrm{~A}$ & $1,18 \mathrm{~A}$ & $72,98 \mathrm{~A}$ & $5,96 \mathrm{~A}$ & $7,6 \mathrm{~A}$ \\
& $\mathrm{SA}$ & $63,91 \mathrm{~A}$ & $1,28 \mathrm{~A}$ & $72,95 \mathrm{~A}$ & $6,08 \mathrm{~A}$ & $7,27 \mathrm{~B}$ \\
\hline \multirow{2}{*}{$26^{\circ} \mathrm{C}$} & $\mathrm{GE}$ & $65,72 \mathrm{~A}$ & $1,11 \mathrm{~A}$ & $73,49 \mathrm{~A}$ & $6,63 \mathrm{~A}$ & $7,41 \mathrm{~A}$ \\
& $\mathrm{SA}$ & $65,17 \mathrm{~A}$ & $1,09 \mathrm{~A}$ & $73,36 \mathrm{~A}$ & $6,58 \mathrm{~A}$ & $7,34 \mathrm{~A}$ \\
\hline & $\mathrm{GE}$ & $58,81 \mathrm{~A}$ & $1,13 \mathrm{~A}$ & $71,40 \mathrm{~A}$ & $6,85 \mathrm{~A}$ & $7,55 \mathrm{~A}$ \\
& $\mathrm{SA}$ & $59,89 \mathrm{~A}$ & $1,09 \mathrm{~A}$ & $71,76 \mathrm{~A}$ & $6,43 \mathrm{~B}$ & $7,36 \mathrm{~A}$ \\
\hline
\end{tabular}

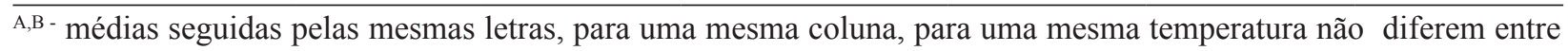
si pelo teste de Tukey $(\mathrm{P}<0,05)$.

336 REVENG 334-339p. 
Conforme apresentado no Quadro 1, observa-se que as médias das massas dos ovos produzidos em gaiola enriquecida e em sistema alternativo em uma mesma temperatura, não revelou diferença significativa $(\mathrm{P}<0,05)$. Resultados semelhantes foram encontrados por Jacome et al., (2007), trabalhando com poedeiras semi-pesadas alojadas em diferentes sistemas de acondicionamento térmico não encontrou diferença significativa $(\mathrm{P}<0,05)$ na massa dos ovos.

As diferenças médias da massa dos ovos, quando se comparou os sistemas de criação (GE e SA) no mesmo ambiente, foram de $0,31 \mathrm{~g}$ para o ambiente de $20^{\circ} \mathrm{C}, 0,55 \mathrm{~g}$ para ambiente de $26^{\circ} \mathrm{C}$ e de $1,08 \mathrm{~g}$ para o ambiente de $32^{\circ} \mathrm{C}$. Estes valores não conferem com os encontrados por Barbosa Filho, (2004), que encontrou diferença de 2,4 g e 3,4 g para aves criadas em gaiolas e sistema de cama nas condições ambientais de $26^{\circ} \mathrm{C}$ e $35^{\circ} \mathrm{C}$.

No mesmo Quadro 1, observam-se os valores médios de massa dos ovos das aves criadas em gaiola enriquecida e nos sistema alternativo no ambiente de $20^{\circ} \mathrm{C}$ e $26^{\circ} \mathrm{C}$, onde a massa menor foi de $63,91 \mathrm{~g}$ e o peso maior foi de $65,72 \mathrm{~g}$. Segundo North, (1993), esses ovos são classificados como tipo 2, considerado extra. Os ovos produzidos no ambiente de $32{ }^{\circ} \mathrm{C}$, segundo o mesmo autor, encontram-se na classificação do tipo 3, considerado grande. Esses valores da massa dos ovos estão em discordância dos encontrados por Barbosa Filho (2004), que observou uma média entre $53 \mathrm{~g}$ para ovos produzidos em cama e $58 \mathrm{~g}$ para ovos produzidos em gaiola.

Em relação às médias dos valores da Unidade de Haugh dos ovos produzidos nos dois sistemas de criação, pode-se observar que houve pouca variação quando comparados com os dois sistemas de criação (GE e SA) e as condições ambientais. Segundo Cherian et al. (1990), quando os ovos são armazenados por longos períodos pode ocorrer redução da massa dos ovos, devido à perda de água e a descentralização da gema, com consequente redução da unidade de Haugh. Nesta pesquisa, não houve período de armazenamento dos ovos, pois os testes foram realizados no mesmo dia da coleta. Dessa forma, os valores encontrados estão de acordo com Silva (2004), que verificou que, ovos com Unidade de Haugh acima de 72 são considerados de excelente qualidade, exceto para os ovos produzidos no ambiente de $32{ }^{\circ} \mathrm{C}$, que apresentaram um leve decréscimo nos valores de Unidade de Haugh, a qual é considerado do Tipo A. Este fato provavelmente ocorreu devido à temperatura do ambiente ser maior, favorecendo a perda de água dos ovos entre o período de postura e da coleta.

Alleoni e Antunes (2001) observaram valores na Unidade de Haugh de 60,63, ao final de 21 dias e armazenamento a $8{ }^{\circ} \mathrm{C}$. Por outro lado, Jones e Musgrove (2005), analisando ovos armazenados a $4{ }^{\circ} \mathrm{C}$ durante 10 semanas, encontraram valores de 67,43 Unidade de Haugh, ao final do período de armazenamento. De acordo com os resultados obtidos neste estudo, observa-se que os valores foram superiores aos encontrados pelos autores acima, este fato provavelmente ocorreu devido às análises terem sidos feitas no mesmo dia de postura, não havendo período de armazenamento.

Em relação ao $\mathrm{pH}$ da gema e $\mathrm{pH}$ da clara (albúmem), observou-se diferença significativa $(\mathrm{P}<0,05)$, nas gaiolas enriquecidas e nos sistema alternativo nas condições ambientais de $20{ }^{\circ} \mathrm{C}$ e $32{ }^{\circ} \mathrm{C}$. A diferença encontrada entre os sistema de criação não foi ocasionado pelo tempo de armazenamento de ovos, pois os mesmos eram coletados e imediatamente realizado os testes. Nesse sentido, pode-se afirmar que não houve perda de $\mathrm{CO}_{2}$ através dos poros da casca por período de armazenamento. Observou-se, ainda, que os valores médios do $\mathrm{pH}$ da clara variou de 7,34 a 7,61, valores semelhantes aos citados por Mine, (1995), que relata que os ovos frescos devem ter uma variação de pH de clara entre 7,6 a 8,5.

Pode-se observar que segundo American Egg Board (1998), os valores do $\mathrm{pH}$ da gema devem ficar em torno de 6,0, semelhante aos encontrados nessa pesquisa. Os valores de $\mathrm{pH}$ encontrados nessa pesquisa conferem com os encontrados por Baptista (2007), que observou nos primeiros 3 dias de armazenamento valores entre 6,1 e 6,3.

Quanto à variável gravidade específica dos ovos, observou-se que também não houve diferença significativa $(\mathrm{P}<0,05)$ entre os sistemas de criação e as condições ambientais. Segundo Rosa e Avila (2000), a gravidade específica é uma medida de cunho físico que avalia a densidade do ovo, à qual se relaciona basicamente com a espessura da casca, sendo responsável por variações nos resultados de incubação. Aves com idade intermediária entre 35 
a 55 semanas produzem ovos com maior GE (1075 a $1090 \mathrm{~g} \mathrm{~g}^{-1}$ ), que estão relacionados a maiores índices de eclosão. Aves velhas, com idade superior a 56 semanas, produzem uma proporção maior de ovos com cascas de qualidade inferior, relacionada a menor gravidade especifica $\left(<1074 \mathrm{~g} \mathrm{~g}^{-1}\right)$. Nesta pesquisa, foram observados valores superiores de gravidade específica $\left(1090 \mathrm{~g} \mathrm{~g}^{-1}\right)$, provavelmente por que as aves tinham idade inferior de 33 semanas, a qual pode ter proporcionando maiores valores de gravidade específica.

Ainda sobre valores de gravidade específica, Peebles e Mcdaniel (2004) consideraram em seu trabalho o valor da gravidade específica 1,0800 $\mathrm{g} \mathrm{g}^{-1}$ como um valor limite entre baixa ou alta qualidade da casca dos ovos, resultado que não confere ao encontrado nesta pesquisa, pois os valores encontrados foram superiores.

Os valores encontrados nesta pesquisa também estão em desacordo com os observados por Alves et al. (2007), onde encontrou em trabalhos com cama e gaiola valores de gravidade especifica entre 1,076 a $1,089 \mathrm{~g} \mathrm{~g}^{-1} \mathrm{em}$ gaiola e valores entre 1,081 a $1,090 \mathrm{~g} \mathrm{~g}^{-1}$, em cama.

\section{CONCLUSÕES}

De acordo com os resultados obtidos para esta pesquisa, pode-se concluir que:

- Não houve diferença significativa $\mathrm{P}(<0,05)$ relacionando com o tipo de sistema de criação, exceto no $\mathrm{pH}$ da clara, na condição ambiental de $20{ }^{\circ} \mathrm{C}$, e no pH da gema, na condição de $32{ }^{\circ} \mathrm{C}$.

- O produtor pode optar em produzir ovos em gaiola enriquecida ou em sistema alternativo, pois os resultados são semelhantes.

- As variáveis de qualidade dos ovos não foram influenciadas pelo sistema de produção.

\section{REFERENCIAS BIBLIOGRÁFICAS}

ALBUQUERQUE, R. Tópicos importantes na produção de poedeiras comerciais. Avicultura Industrial, v.1121, n.95, 2004.

ALLEONI, A.C.C.; ANTUNES, A.J. Unidade Haugh como medida da qualidade de ovos de galinha armazenados sob refrigeração. Scientia Agrícola, v.58, n.4, p.681-685, 2001.
ALVES, S.P.; SILVA, I.J.O.; PIEDADE, S.M.S. Avaliação do bem-estar de aves poedeiras comerciais: efeitos do sistema de criação e do ambiente bioclimático sobre o desempenho das aves e a qualidade de ovos. Revista Brasileira Zootecnia., v.36, n.5, p.1388-1394, 2007.

BARBOSA FILHO, J.A.D.; SILVA, I.J.O.; SILVA, M.A.N.; SILVA, C.J.M. Avaliação dos comportamentos de aves poedeiras utilizando sequência de imagens. Engenharia Agrícola, Jaboticabal, v.27, n.1, p.93-99, 2007.

BAPTISTA, R.F.; KOECH, K.P.; RIBEIRO, R.O.R.; MÁRSICO, E.T.; MANO, S.B. Influência do trincamento da casca do ovo sobre sua qualidade comercial. Revista Brasileira de Ciência Veterinária. v.14, n.1, p.35-38, jan/fev. 2007.

BRASIL. Ministério da Agricultura, Pecuária e Abastecimento. Regulamento de Inspeção Industrial e Sanitária de Produtos de Origem Animal. Decreto $\mathrm{n}^{\circ}$ 30.691, de 29 de março de 1952, e alterações. Diário Oficial da União. Brasília, 1997. Disponível em: www.agricultura. gov.br>. Acesso em: 27 de setembro de 2011.

CAMPOS, J.E. Arquivos da Escola de Medicina Veterinária, v.25, n.3. Órgão de Publicação Oficial do Centro de Pesquisas Veterinárias UFMG. Belo Horizonte. p.212-215, 1973.

CHERIAN, G.; LANGEVIN, C.; AJUYAL, A.; LIEN, K.; SIM, J.S. Research note: Effect of storage conditions and hard cooking on peelability and nutrient density of white and brown shelled eggs. Poultry Science, v.69, p.1614-1616, 1990.

COSTA, F.G.P; SOUZA, C.J; GOULART, C.C. Desempenho e qualidade de ovos de poedeiras semipesadas alimentadas com dietas contendo óleos de soja e canola. Revista Brasileira de Zootecnia. v.37, n.8, p.1412-1418, 2008.

FURLAN, R.L.; MACARI, M.; MATEUS, J.R. . Bem estar das aves e suas implicações sobre o desenvolvimento e produção. Disponível em: $<$ http://www.engomix.com/bem__ estar_das aves_p_artigos_17_AVG.htm $>$. Acesso em: 21/10/2011. 
HEMPE, J.K.; LAUXWN, R.C.; SAVAGE, J.E. Rapid determination of egg weight and specific gravity using a computerized data collection system. Poultry Science, v.67, p.902-907, 1988.

JÁCOME, I.M. T.D.; FURTADO, D.A.; LEAL, A.F.; SILVA, J.H.V. Avaliação de índices de conforto térmico de instalações para poedeiras no nordeste do Brasil. Revista Brasileira de Engenharia Agrícola e Ambiental, v.11, n.5, p.527-531, 2007.

JONES, D.R.; MUSGROVE, M.T. Effects of extended storage on egg quality factors. Poultry Science, v.84, p.1774-1777, 2005.

MINE, Y. Recents advances in the understanding of egg white protein functionally. rends in Food Sci. and Technol. 1995, v.6, n.7, p.225-232.

PARDI, H.S. Influência da comercialização na qualidade dos ovos de consumo. Niterói-RJ: Universidade Federal Fluminense, 1977. 73p.

PEEBLES, E.D; McDANIEL, C.D.A practical manual for understading the shell structure of broiler hatching eggs and measurements of their quality. Mississipi: State University, 2004.

ROSA, P.S; AVILA, V.S. Variáveis relacionadas ao rendimento de incubação de ovos em matrizes de frango de corte. Comunicado Técnico/ 246/ Embrapa Suínos e aves, p.1-3 Maio -2000.

SCOTT, T.A.; SILVERSIDES, F.G. The effect of storage and strain of hen on egg quality. Poultry Science, v.79, p.1725- 1729, 2001.

SILVA, F. H. A. Curso teórico prático sobre técnicas básicas de avaliação da qualidade do ovo. NUPEA/ ESALQ - USP. Departamento de Zootecnia/ FZEA - USP. Piracicaba, junho 2004.

SILVERSIDES, F.G.; BUDGELL, K. The relationships among measures of egg albumen height, $\mathrm{pH}$, and whipping volume. Poultry Science, v.83, p.1619-1623, 2004.

TAUSON, R. Management and housing systems for layers-efects on welfare and production. World's Poultry Science Journal, v.61, p.477-490, 2005. 